\title{
Short-Pulse Resistance Spot Welding of Aluminum Alloy 6016-T4 - Part 1
}

\author{
The influence of welding time and current on weld quality was investigated
}

BY E. SCHULZ, M. WAGNER, H. SCHUBERT, W. ZHANG, B. BALASUBRAMANIAN, AND L. N. BREWER

\begin{abstract}
Short-pulse welding parameters for resistance spot welding (RSW) of aluminum alloy AA6016-T4 using mediumfrequency direct current (MFDC) systems were developed to reduce the heat input required for nugget formation. Optimization of current and time parameters is critical during RSW of aluminum alloys for reducing energy requirements and avoiding weld imperfections, such as solidification cracking and expulsion, while maintaining weld quality, particularly given the high electrical and thermal conductivities of the materials. The welding time and the applied current level of the current pulse were varied systematically for thin sheets ( $1 \mathrm{~mm}$ or $0.04 \mathrm{in}$.) of AA6016-T4. The quality of the welds was evaluated by pull-out testing, ultrasound testing, and metallography techniques. Simulations of the same welding processes were performed with the finite element-based SORPAS ${ }^{\circledR}$ software. The results showed short-pulse MFDC RSW can reduce the energy required for sound welds in this alloy without requiring an increase in welding current. The simulations and experiments also showed the welding process had distinct weld nugget nucleation and growth phases.
\end{abstract}

\section{KEYWORDS}

- Resistance Spot Welding (RSW) • Aluminum Alloys

- Welding Parameters $\bullet$ Numerical Simulation

\section{Introduction}

The use of aluminum materials in automotive bodyin-white construction has become more widespread as manufacturers pursue vehicle lightweighting strategies to meet strict fuel-efficiency requirements. The body-in-white represents approximately $30 \%$ of the total vehicle weight, and hybrid construction concepts using a mix of steel and alu- minum parts provide an opportunity for reducing vehicle weight (Ref. 1). Aluminum alloys from the 5000 and 6000 series are now widely used for body-in-white construction, and joining tasks exist over a range of sheet thicknesses and material combinations. For these joining tasks, suitable joining methods are needed.

Resistance spot welding (RSW) is an established joining technology for automotive body structures, but its application to aluminum alloys presents special challenges. The electrical and thermal conductivity of aluminum is much higher than of steel, which leads to much higher welding currents for successful joining. Aluminum alloy AA6016-T4 has a particularly high thermal conductivity of $190 \mathrm{~W} / \mathrm{mK}$ (92.4 $\mathrm{Btu} / \mathrm{hftF}$ ), which requires especially high welding currents to enable a stable welding process. High welding currents, however, increase energy requirements and can lead to a number of disturbances in the welding process, such as large magnetic forces that cause the gun arms to deflect from each other, solidification cracking, expulsion, and rapid electrode wear (Refs. 2-4). Progress on RSW of aluminum alloys has been reported in recent welding literature with regards to the influence of electrode geometry (Ref. 5), surface pretreatments (Refs. 6-8), and, to some degree, parameterization on the process (Refs. 9, 10). Some information was also presented on the weld nugget nucleation and growth processes for alloy AA5182 (Ref. 11). However, until now, the literature has focused primarily on AA5182, and knowledge remains to be gained on AA6016-T4, which is highly sensitive to the RSW process in terms of process stability and electrode wear.

The influence of welding parameters on the heat input and generation of the weld nugget requires further investigation for RSW of AA6016-T4. In particular, the role of the current-pulse duration, or welding time, is of key concern. Recent research on capacitive discharge (CD) welding has shown that high current levels applied over very short time durations (e.g., on the order of 5 to $20 \mathrm{~ms}$ ), can allow for the 


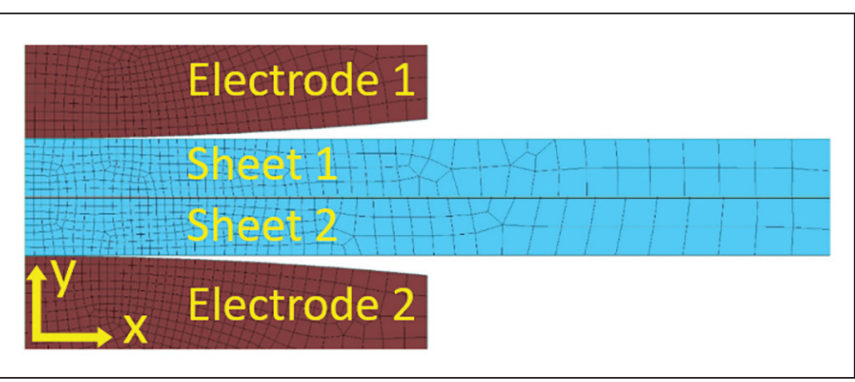

Fig. 1-Numerical system for welding simulations with the SORPAS software.

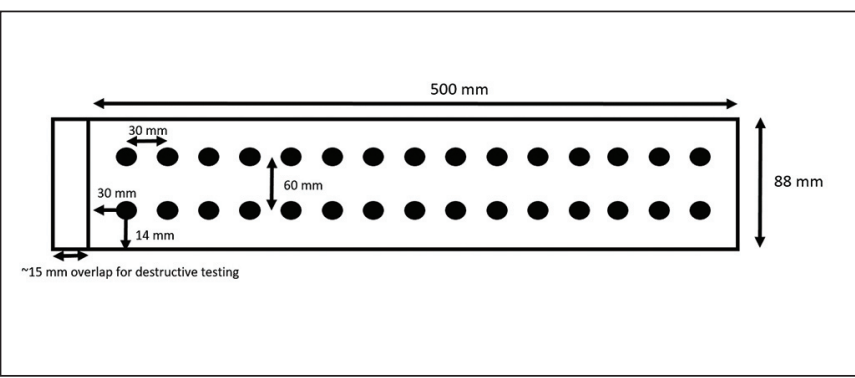

Fig. 2 - Experimental sample geometry and weld configuration.

Table 1 - Chemical Composition of AA6016-T4 by wt-\%

\begin{tabular}{cccccccccc}
$\mathrm{Al}$ & $\mathrm{Si}$ & $\mathrm{Fe}$ & $\mathrm{Cu}$ & $\mathrm{Mn}$ & $\mathrm{Mg}$ & $\mathrm{Cr}$ & $\mathrm{Zn}$ & $\mathrm{Ti}$ & $\mathrm{V}$ \\
\hline $96.4-98.8$ & $\leq 1.50$ & $\leq 0.50$ & $\leq 0.25$ & $\leq 0.40$ & $\leq 1.00$ & $\leq 0.15$ & $\leq 0.30$ & $\leq 0.25$ & $\leq 0.15$ \\
\hline
\end{tabular}

successful welding of difficult alloys such as EN AW-7075, which suffers from solidification cracking under normal welding conditions (Ref. 12).

Short-pulse techniques in the context of RSW have also been applied to high-strength steel materials to reduce expulsion using medium-frequency direct current (MFDC) systems (Ref. 13) and to 5000 series aluminum alloys using CD systems to improve electrode wear characteristics (Ref. 10). In addition to these benefits, the use of short welding times with the $C D$ systems reduces the heat input needed to make a successful weld and limits heat losses by conduction for high-conductivity materials. However, MFDC systems remain most attractive for automotive manufacturers given the cost and availability as well as the ability to control parameters in real time during the welding process. Given the prevalence of RSW in the automotive industry and the necessity for a long-term solution for joining 5000 and 6000 series aluminum alloys, the following question arises: Can short-pulse welding be performed using a MFDC technology that provides the benefits of low heat inputs?

This paper will systematically show that MFDC RSW for AA6016-T4 can benefit significantly from short-time current-pulse parameters with resultant high-quality welds at low welding currents. Both experimental and simulation results are used to show how the current-pulse duration and applied current level affect the nucleation and growth of the fusion zone.

\section{Materials}

The commercial aluminum alloy AA6016-T4, with nominal chemical composition and mechanical properties as listed in Tables 1 and 2, was the subject of this study. Material sheets in thicknesses from 1.0 to $2.0 \mathrm{~mm}$ (0.04 to 0.08 in.) in an as-received, pretreated condition were used. The pretreatment process was carried out according to the VDA 239-200, Aluminum Sheet Material, standard (Ref. 14). This included surface passivation to establish a reduced and consistent oxide layer thickness followed by application of forming oil in accordance with company standards.

\section{Numerical Methods}

The commercially available SORPAS ${ }^{\circledR}$ 2D Welding software package was used to simulate the RSW process. The software contains a module specific to the RSW process and databases of material, machine, electrode, and workpiece properties (Ref. 15). The solution algorithm contains mechanical, electrical, and thermal models within each time step as well as full coupling between the electrical and thermal models. A two-dimensional (2D), axisymmetric model of the welding process, including electrodes and sheets, was created in the SORPAS 2D Welding software. Due to the rotational symmetry around the vertical axis through the center of the electrodes and sheets, one half of the electrodes and sheets was represented in the model. Meshing of the system was completed using the automatic meshing feature with high-mesh density in the regions of large temperature gradients and mechanical deformation - Fig. 1.

The SORPAS software is based on the finite element method (FEM). It solved the governing differential equations below for electrical potential, transient heat transfer, and plastic deformation, respectively after discretization of the system using FEM formulations in two dimensions (Ref. 16).

$$
\begin{aligned}
& \frac{\partial}{\partial x}\left(\sigma_{x} \frac{\partial \varphi}{\partial x}\right)+\frac{\partial}{\partial y}\left(\sigma_{y} \frac{\partial \varphi}{\partial y}\right)=0 \\
& \frac{\partial}{\partial x}\left(k_{x} \frac{\partial T}{\partial x}\right)+\frac{\partial}{\partial y}\left(k_{y} \frac{\partial T}{\partial y}\right)+\dot{Q}=\rho C \frac{\partial T}{\partial t} \\
& \pi=\int_{V} \bar{\sigma} \dot{\bar{\varepsilon}} d V-\int_{S} F v d S, \quad \frac{\partial \pi}{\alpha \nu}=0
\end{aligned}
$$

For the electrical and thermal models, the material properties involved were $\sigma$, the electrical conductivity; $k$, the thermal conductivity; $\rho$, the mass density; and $C$, the heat capacity. $\dot{Q}$ was the internal heat energy source term. The time-dependent distributions of electrical potential, $\Phi$, and 


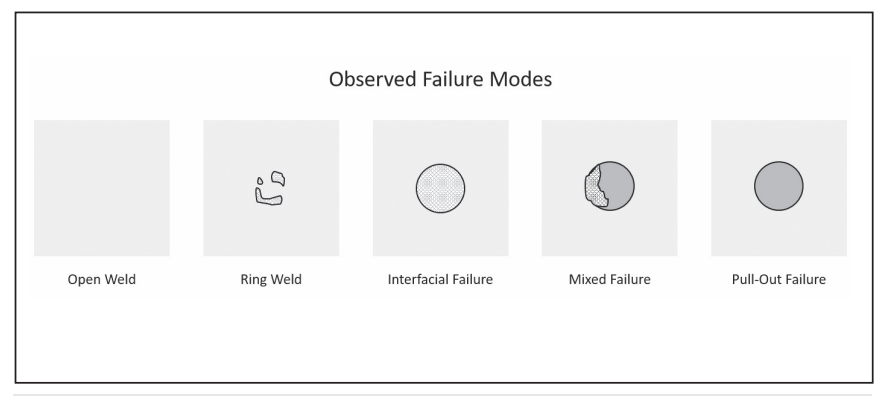

Fig. 3 - Failure modes in experimental pull-out tests.

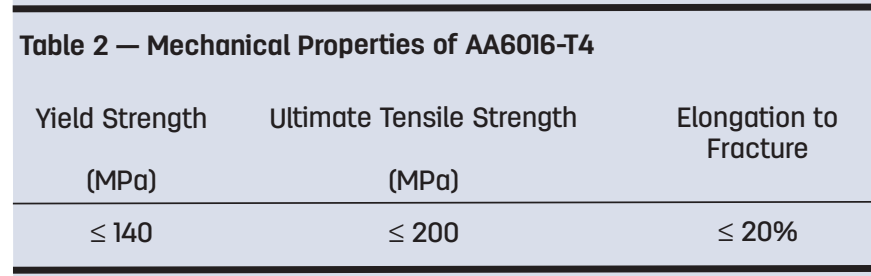

temperature, $T$, were calculated at each time step. For the mechanical model, deformation and contact areas were calculated at each time step by the variation approach for plastic deformation (Equation 3). Electrical contact resistivity at the interfaces between electrodes/sheets and sheets/sheets was calculated according to Wannheim and Bay's friction theory for real contact areas (Ref. 16):

$$
\rho_{\text {contact }}=3\left(\frac{\sigma_{s_{\text {soft }}}}{\sigma_{n}}\right)\left(\frac{\rho_{1}+\rho_{2}}{2}+\rho_{\text {contaminants }}\right)
$$

In the contact resistivity formulation, $\sigma_{s_{s} \text { soft }}$ represents the flow stress of the softer material in contact, $\sigma_{n}$ is the normal pressure at the interface, and $\rho_{1}$ and $\rho_{2}$ are the temperature-dependent base material resistivity values of the two materials in contact. The $\rho_{\text {contaminants }}$ term accounts for the additional contact resistance introduced by the surface layer between the materials, such as from oxide layers, contamination, or pretreatment layers on the surface.

Detailed temperature-dependent material properties were available for a range of aluminum alloys in the software database, including for the alloy of interest. However, due to differences in manufacturers, pretreatment, age of the material, and other factors that affect the characteristics of the material surface, the contact resistivity functions had to be adjusted in the material model. Although base material properties do not show large variations within a given alloy designation, it was shown in Al Naimi et al. (Ref. 7) and Crinon et al. (Ref. 17) that there are large variations in resistances of the surface layers when roughness or characteristics of the oxide layer are changed via pretreatment processes. Therefore, it was necessary to calibrate the material model for the experimental material of interest to improve the accuracy of the simulation results.

Calibration of the model was performed by a linear scaling of surface resistivity values $\left(\rho_{\text {contaminants }}\right)$ in the material model after comparison of the weld nugget diameter from the simulations to a small series of experimental pull-out tests. The tests were completed for the combination of two

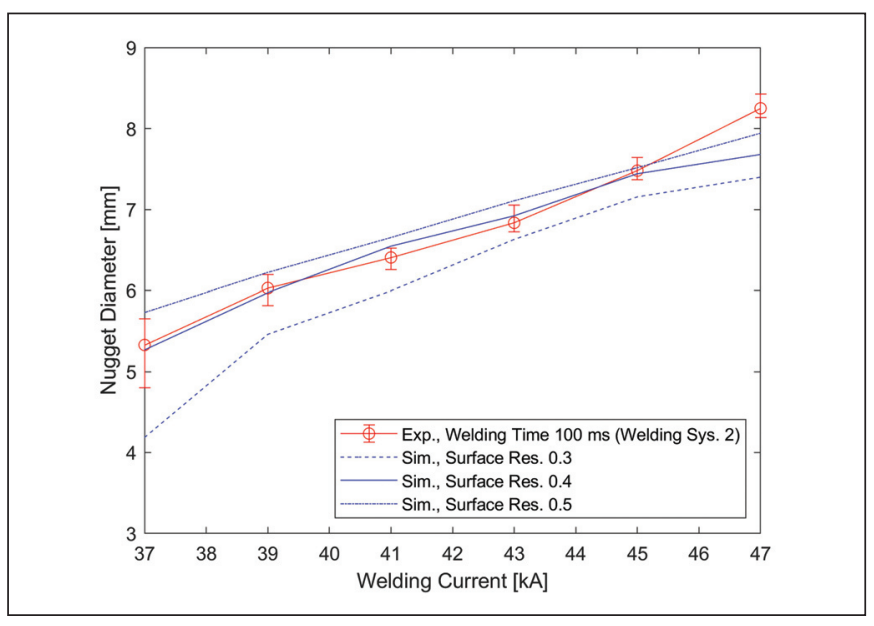

Fig. 4 - Simulation model calibration by variation of the surface resistivity factor using data from pull-out testing of welding system 2 (sheet thickness of $1.5 \mathrm{~mm}$ ).

sheets of AA6016-T4 with a thickness of $1.5 \mathrm{~mm}$ (0.06 in.). A fixed welding time of $100 \mathrm{~ms}$ and a current range of 27 to $37 \mathrm{kA}$ were used as welding parameters. The starting current value in the range was chosen as that which produced a weld nugget of approximately $4 \sqrt{ }\left(t_{\min }\right)$, where $t_{\min }$ is the minimum sheet thickness in the combination. This nugget diameter corresponds to the minimum weld size required. Five welding spots were made at each welding current value for increased precision. After establishing the necessary scaling value, additional tests were made to assess the model with further changes in welding conditions. Two additional sheet thicknesses, of 1 and $2 \mathrm{~mm}$ (0.04 and $0.08 \mathrm{in}$.), were considered as well as a variation of welding times. The results of the simulations and a discussion of the robustness of the model are presented in the following sections.

\section{Experimental Procedures}

Experimental tests were carried out using two MFDC machines with different power capabilities to evaluate the potentials for short-pulse welding. The first welding machine, referred to as welding system 1 , included the MFDC inverter and control unit model PRC7000 from Bosch Rexroth as well as the Daimler-specified C-shaped welding gun construction from Düring Schweißtechnik GmbH. The Bosch Rexroth PSG 6180 welding transformers with a switching frequency of $1000 \mathrm{~Hz}$ as well as power ratings of $80 \mathrm{kVA}$ at a $100 \%$ duty cycle and $178 \mathrm{kVA}$ at a $20 \%$ duty cycle were connected in parallel for a maximum output current of approximately $50 \mathrm{kA}$.

The second welding machine, welding system 2 , had a Nimak GmbH magnetic-drive system. The system included a control unit with Bosch Rexroth MFDC inverter components and a Nimak C-shaped gun geometry for short-pulse welding. The welding transformers used were the Nimaktype NMFT 1260 with a switching frequency of $1000 \mathrm{~Hz}$ as well as power ratings of $116 \mathrm{kVA}$ at $100 \%$ duty cycle and 260 $\mathrm{kVA}$ at $20 \%$ duty cycle. Output currents up to $80 \mathrm{kA}$ were possible but limited to $60 \mathrm{kA}$ due to limitations on connector components. For the purposes of this study, the welding 

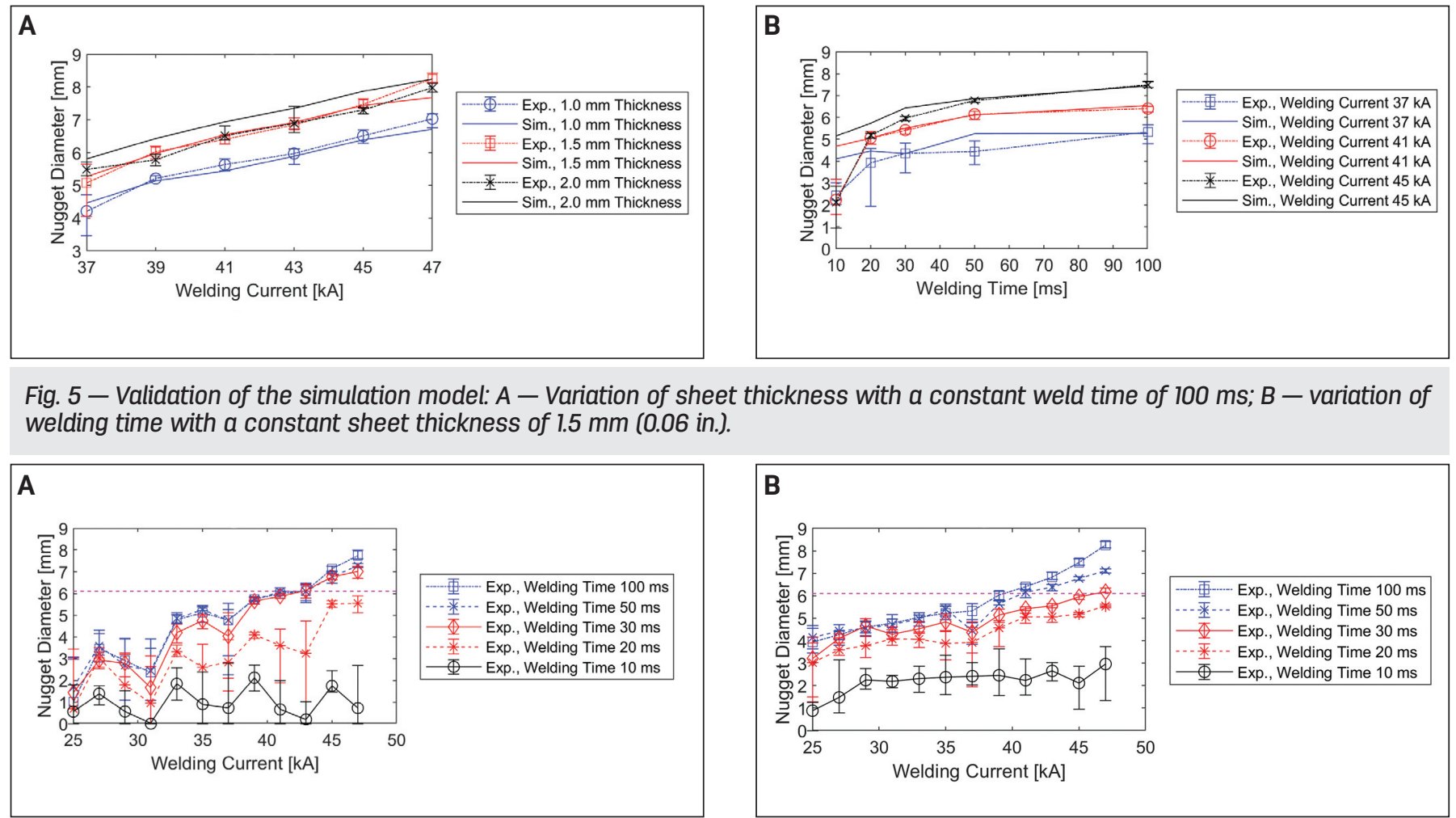

Fig. 5 - Validation of the simulation model: A - Variation of sheet thickness with a constant weld time of $100 \mathrm{~ms}$; B - variation of welding time with a constant sheet thickness of $1.5 \mathrm{~mm}$ (0.06 in.).

Fig. 6 - Experimental pull-out data for welding systems $1(A)$ and 2 (B). The required nugget diameter of $6.1 \mathrm{~mm}(0.24$ in.) is represented by a dotted line in the color magenta.

current was limited to a maximum of $47 \mathrm{kA}$. Both welding systems operated under closed loop, constant current, and constant force control. In all cases, Luvata copperchromium-zinc electrodes with an A0-type geometry and an outer diameter of $20 \mathrm{~mm}$ were used, in accordance with the German standard DIN EN ISO 5821, Resistance Welding Spot Welding Electrode Caps (Ref. 18).

For experimental tests, the aluminum material was cut into samples of $500 \times 88 \mathrm{~mm}(19.4 \times 3.5 \mathrm{in}$.). This geometry enabled 30 welding spots to be made on each sample. Spots were placed at equal distances, and minimum spacing values were upheld to prevent shunting effects from neighboring welds. The welding sample geometry is shown in Fig. 2. Electrodes were redressed by mechanical cutting every 15 spots

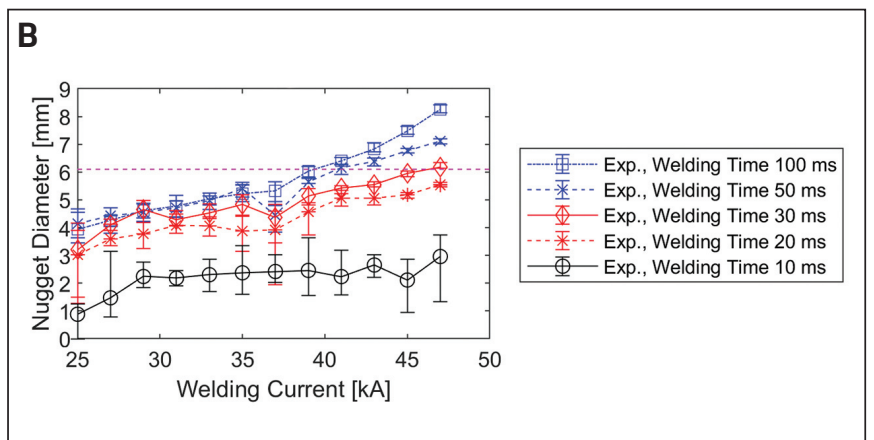

to maintain consistent electrode surfaces.

Experimental weld nugget diameters were determined by pull-out testing on an internally designed machine. Fracture modes were classified according to Fig. 3 and recorded. Allowable current ranges for a given welding time were determined for each set of parameters based on pull-out data. These current ranges were defined by a starting current level for which all welds had a diameter greater than or equal to $5 \sqrt{t_{\text {min }}}$ (required nugget diameter with the added factor of safety from the minimum diameter). The upper limit of the current range was defined as either the maximum allowable current $(47 \mathrm{kA})$ or the lowest current level at which expulsion was observed. During tests, a Spatz Multi04 welding recorder was used to record the current and voltage signals

Table 3 - Prevalent Fracture Modes From Destructive Testing, Welding System 1 (Bosch PRC7000)

\begin{tabular}{|c|c|c|c|c|c|}
\hline $\begin{array}{l}\text { Welding Current } \\
\text { (KA) }\end{array}$ & $10 \mathrm{~ms}$ & $20 \mathrm{~ms}$ & $30 \mathrm{~ms}$ & $50 \mathrm{~ms}$ & $100 \mathrm{~ms}$ \\
\hline 25 & Open weld 60\% & Open weld $80 \%$ & Open weld $40 \%$ & Interfacial 60\% & Open weld 60\% \\
\hline 27 & Ring $100 \%$ & Interfacial $100 \%$ & Interfacial $100 \%$ & Interfacial 60\% & Interfacial $80 \%$ \\
\hline 29 & Open weld $60 \%$ & Interfacial 60\% & Interfacial 80\% & Pull-out 40\% & Interfacial $80 \%$ \\
\hline 31 & Open weld $100 \%$ & Open weld $60 \%$ & Open weld $40 \%$ & Interfacial 60\% & Interfacial 60\% \\
\hline 33 & Ring $100 \%$ & Interfacial $60 \%$ & Pull-out 100\% & Pull-out 100\% & Pull-out 80\% \\
\hline 35 & Open weld $60 \%$ & Pull-out $40 \%$ & Pull-out $80 \%$ & Pull-out $100 \%$ & Pull-out 100\% \\
\hline 37 & Open $60 \%$ & Pull-out 60\% & Pull-out 60\% & Pull-out 80\% & Pull-out 100\% \\
\hline 39 & Interfacial 60\% & Pull-out 100\% & Pull-out 100\% & Pull-out 100\% & Pull-out 100\% \\
\hline 41 & Open 60\% & Pull-out 60\% & Pull-out 100\% & Pull-out 100\% & Pull-out 100\% \\
\hline 43 & Open $80 \%$ & Pull-out 60\% & Pull-out 100\% & Pull-out 100\% & Pull-out 100\% \\
\hline 45 & Ring $100 \%$ & Pull-out 100\% & Pull-out 100\% & Pull-out 100\% & Pull-out 100\% \\
\hline 47 & Open $60 \%$ & Pull-out 100\% & Pull-out 100\% & Pull-out 100\% & Pull-out 100\% \\
\hline
\end{tabular}




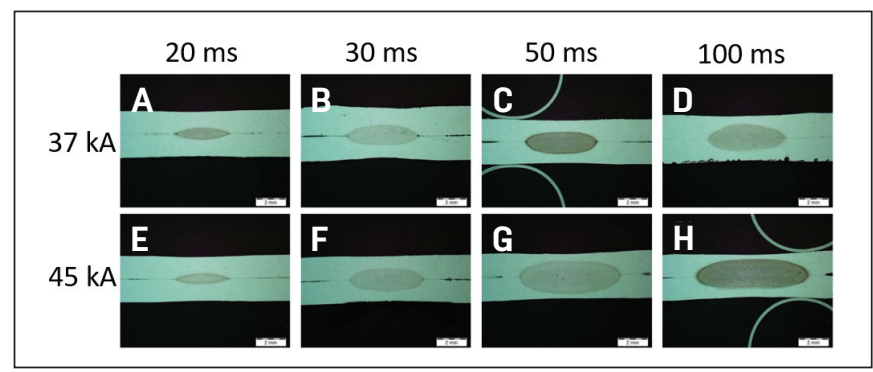

Fig. 7-Optical microscopy images of samples from welding system 2 for two current levels: $A-D-37 \mathrm{kA}$; $E-H-45 \mathrm{kA}$. Images $A$ and $E$ show a welding time of $20 \mathrm{~ms}$, images $B$ and $F$ show a welding time of $30 \mathrm{~ms}$, images $C$ and $G$ show a welding time of $50 \mathrm{~ms}$, and images $D$ and $H$ show a welding time of $100 \mathrm{~ms}$.

to be used for resistance and energy calculations.

Additional welded samples were inspected using nondestructive ultrasonic testing to measure nugget diameter and observe development and growth. The Mini Scanner ultrasonic device from AmsTech was used; it utilizes a scanning pulse-echo technology for high-resolution ultrasonic imaging of the weld area. Cross-sectioned samples were also prepared and polished according to standard metallography techniques and inspected by optical microscopy after etching in a $5 \%$ sodium hydroxide solution for $60 \mathrm{~s}$. The Leitz DMRM microscope from Leica and the SZX12 microscope from Olympus were used.

\section{Results}

\section{Welding Simulation Calibration and Evaluation}

A scaling constant was obtained for surface resistivity values of AA6016-T4 in the SORPAS material database, with good agreement obtained between the simulated weld nugget diameter and the experimental results. The scaling factor found most suitable for the experimental material used in this study was 0.4 , and it remained constant for all further simulations. Experimental results from both welding systems were used for the calibration process, and good agreement was obtained for both. A comparison between the simulation results using three different scaling factors

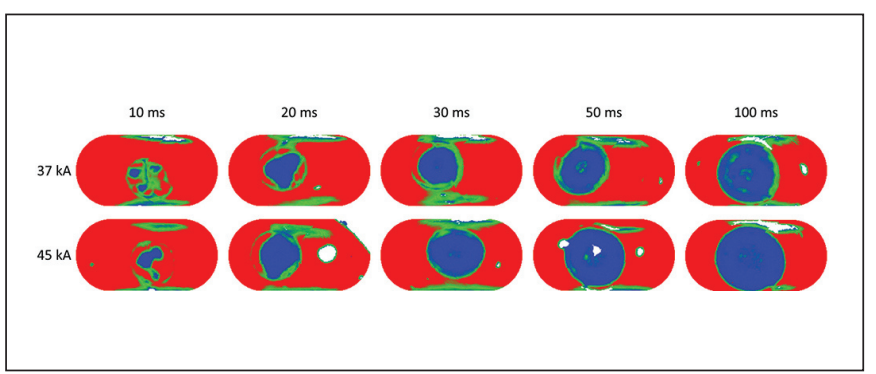

Fig. 8 - Ultrasonic results for the nugget development process and experimental samples from welding system 2 at the listed current and welding time conditions. The blue color represents the areas of fusion, green represents partial fusion or weak signal, and red represents areas of no fusion.

and the experimental results from welding system 2 is shown in Fig. 4. Welding time was set to $100 \mathrm{~ms}$ and the current varied from 37 to $47 \mathrm{kA}$.

The robustness of the new material model was then evaluated by variation of two additional parameters: the material sheet thickness and the welding time. In the first set of tests, the welding time was left constant at $100 \mathrm{~ms}$, and additional sheet thicknesses 1.0 and $2.0 \mathrm{~mm}$ (0.04 and $0.08 \mathrm{in}$.) were tested. As seen in Fig. 5A, a reasonable agreement between the simulations and experiments was maintained. However, a nearly constant difference in weld nugget diameter of approximately $0.5 \mathrm{~mm}$ (0.02 in.) was evident for the largest sheet thickness of $2.0 \mathrm{~mm}(0.08 \mathrm{in}$.). For the next set of tests, the original sheet thickness of $1.5 \mathrm{~mm}$ (0.06 in.) was used, and the welding time decreased from the original time of 100 to $10 \mathrm{~ms}$. Figure 5B shows the comparison between simulated and experimental results. Good agreement in results was obtained for all welding times greater than or equal to $20 \mathrm{~ms}$, regardless of current level. When the welding time was further reduced to $10 \mathrm{~ms}$, discrepancy in results existed. This discrepancy can be explained by the difference in current profiles between the simulation, which utilized idealized current profiles with an infinite current rise speed, and the actual current profiles obtained during experiments. Due to the limited current rise speed of the welding machines, there was a large difference in total heat input between simulations and experiments at short welding times, which explains the difference in the final welding result.

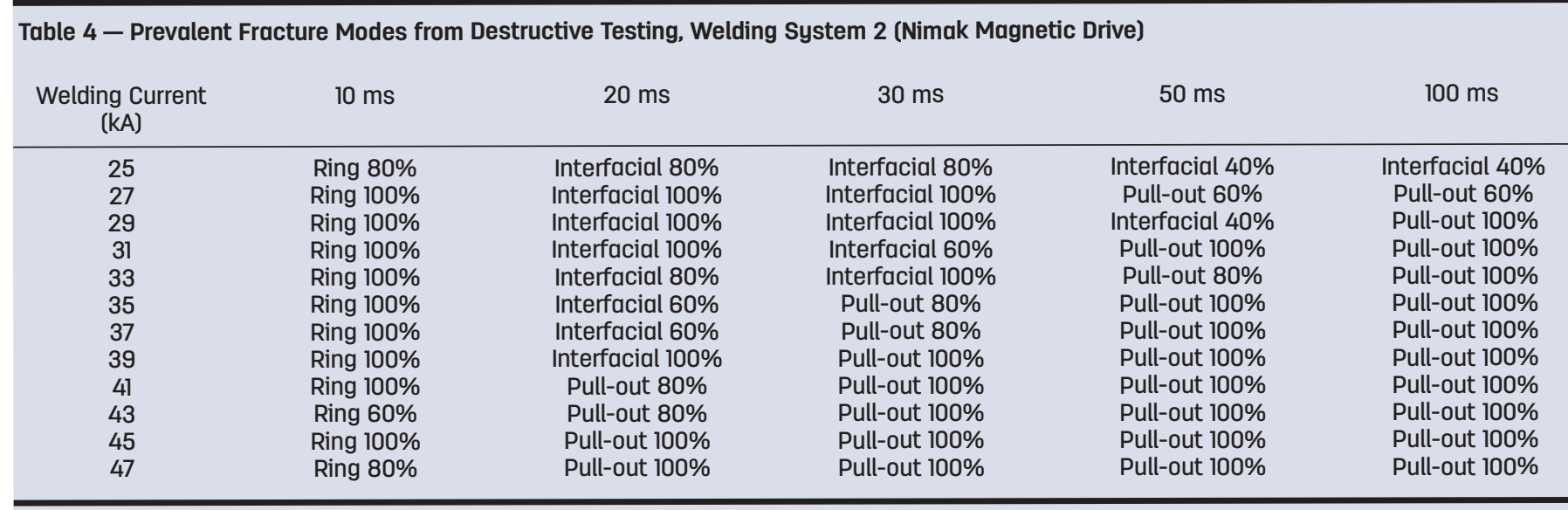




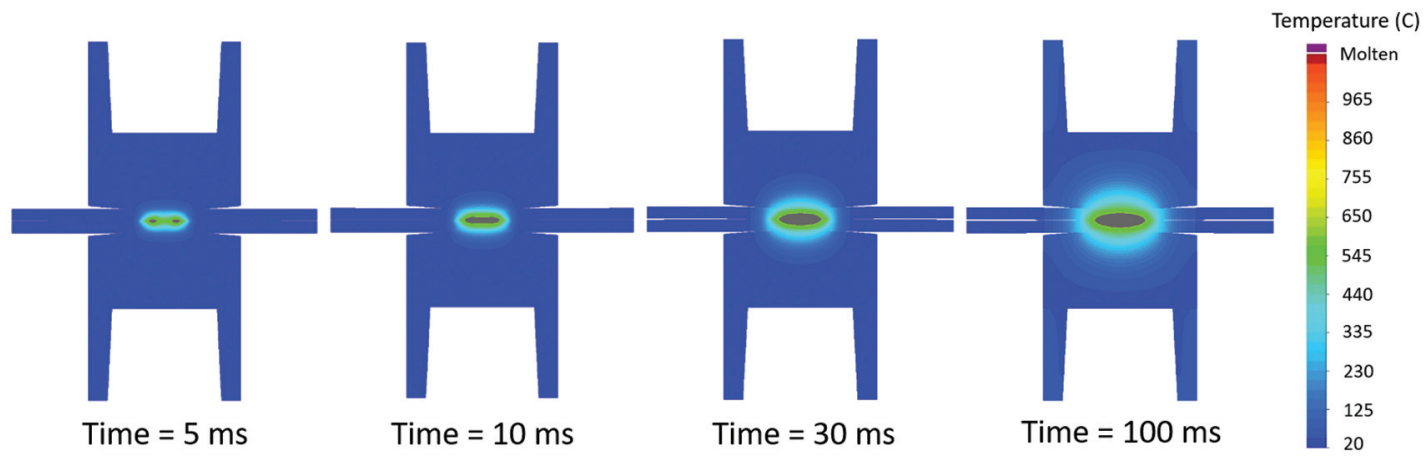

Fig. 9-Nugget development process for a 100-ms, 41-KA welding pulse.

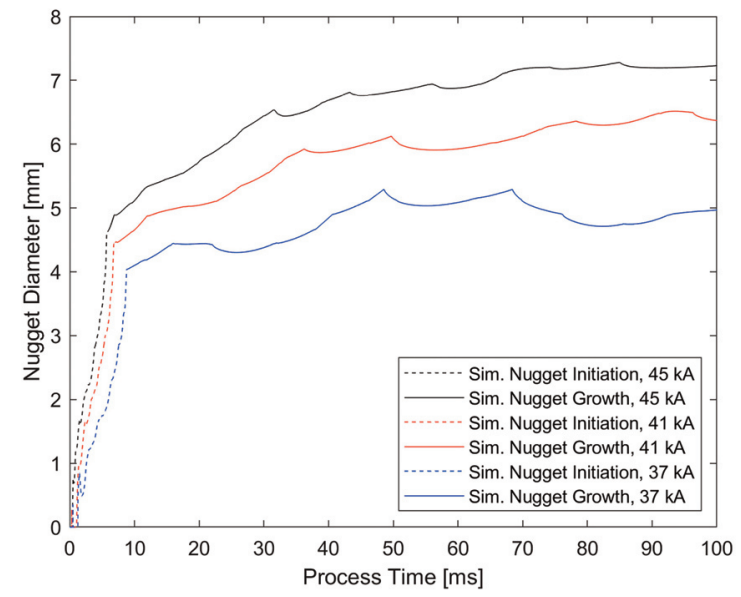

Fig. 10 - Dynamic weld nugget size from simulation data: shown for a 100-ms welding time and welding currents of 37 , 41 , and $45 \mathrm{kA}$.

\section{Weld Nugget Diameter and Failure Mode as a Function of RSW Parameters}

The parameters tested in the previous section were used as the starting point for determining the minimum welding time necessary for the short-pulse welding of AA6016-T4 in 1.5-mm (0.06-in.) sheet thickness, and allowable current ranges as a function of welding time were determined for each of the two systems. Minimum required nugget diameter for this sheet thickness was calculated to be $4.9 \mathrm{~mm}$ (0.19 in.), while the required nugget diameter for the current range determination was $6.1 \mathrm{~mm}$ (0.24 in.). Using 100 $\mathrm{ms}$ as the starting value, the welding time was reduced to

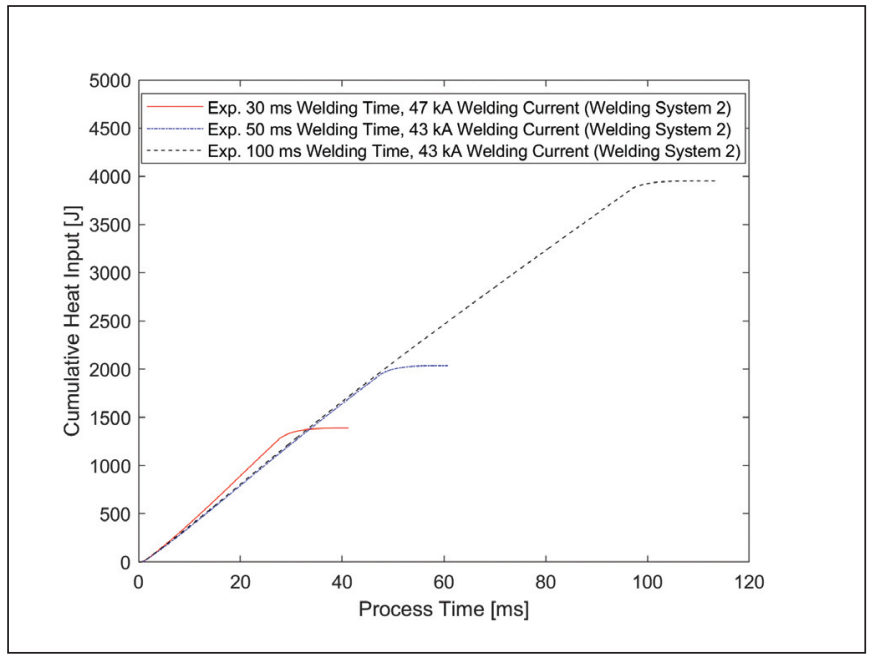

Fig. 11 - Total weld energy input measured experimentally for the welding times of 30,50 , and $100 \mathrm{~ms}$, with current levels corresponding to the equally required final nugget diameter.

$50,30,20$, and $10 \mathrm{~ms}$. For each welding time, the current was varied from 27 to $47 \mathrm{kA}$, and pull-out testing was performed on the welded samples. As expected, an increase in either welding time or current resulted in a larger weld nugget diameter. However, while the increase in the nugget diameter with the increased current was generally linear, the increase in diameter with time was highly nonlinear. Figure $6 \mathrm{~A}$ and $\mathrm{B}$ shows the results of pull-out testing for welding systems 1 and 2, respectively. The weld nugget diameter increased significantly between the welding times of 10 and $20 \mathrm{~ms}$ for both welding systems, showing that the growth rate during this stage of the process was high. Significant nugget growth continued up to $30 \mathrm{~ms}$ for welding system 1 ,

Table 5 - Weld Nugget Nucleation and Growth Rates from Simulation Data for 100-ms Welding Time and 37-, 41-, and 45-kA Welding Currents

\begin{tabular}{cccccc}
$\begin{array}{c}\text { Welding Current } \\
\text { (KA) }\end{array}$ & $\begin{array}{c}\text { Time, } \\
\text { Nucleation Stage } \\
(\mathrm{ms})\end{array}$ & $\begin{array}{c}\text { Growth Rate, } \\
\text { Nucleation Stage } \\
(\mathrm{mm} / \mathrm{ms})\end{array}$ & $\begin{array}{c}\text { Correlation } \\
\text { Coefficient, } \\
\text { Nucleation Stage }\end{array}$ & $\begin{array}{c}\text { Growth Rate, } \\
\text { Growth Stage } \\
\text { (mm/ms) }\end{array}$ & $\begin{array}{c}\text { Correlation } \\
\text { Coefficient, } \\
\text { Growth Stage }\end{array}$ \\
\hline 37 & 9 & 0.374 & 0.96 & 0.008 \\
41 & 7 & 0.568 & 0.97 & 0.018 & 0.39 \\
45 & 6 & 0.746 & 0.95 & 0.022 & 0.87 \\
\hline
\end{tabular}




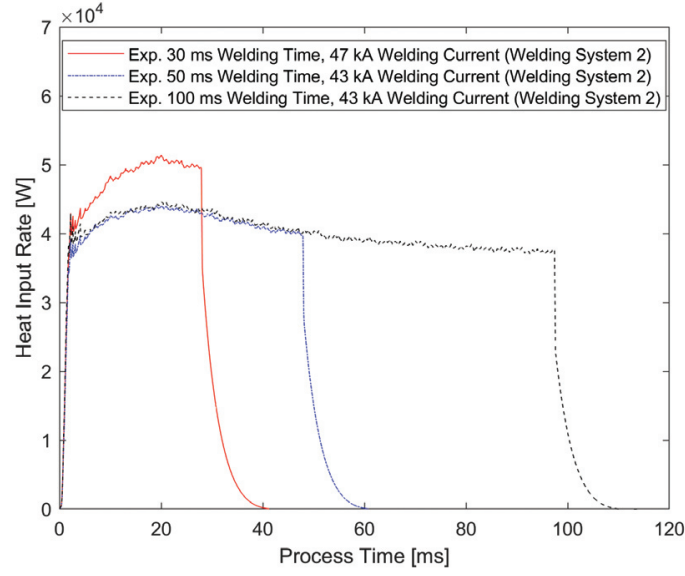

Fig. 12 - Heat energy input rate, measured experimentally for the welding times of 30,50 , and $100 \mathrm{~ms}$. Current levels selected for equally required final nugget diameter.

while the growth rate of the nugget decreased steadily after $20 \mathrm{~ms}$ for welding system 2 . For both systems, the growth rate decreased significantly past a welding time of $30 \mathrm{~ms}$.

For both welding systems, the acceptable current range was equal for the 50- and 100-ms welding time. No expulsions were detected during testing for any conditions; therefore, the current ranges extended to the maximum current of $47 \mathrm{kA}$. For welding system 1 , the current range for both welding times was from 45 to $47 \mathrm{kA}$, and for welding system 2, it was from 43 to $47 \mathrm{kA}$. The $30-\mathrm{ms}$ welding time had a current range of 45 to $47 \mathrm{kA}$ for welding system 1 but no acceptable current range for welding system 2 . At welding times lower than 30 $\mathrm{ms}$, there was a high amount of scatter in the results, and no acceptable current range was obtained. The difference in results between the welding systems was a result of the different current control characteristics and current rise speeds, resulting in different heat inputs to the weld.

Tables 3 and 4 show the most prevalent fracture modes of the pull-out samples for all welding time and current conditions. At the 10-ms welding time, there were a high number of open welds and ring-shaped failures, showing that melting initiated at the periphery and that growth into a solid weld nugget was incomplete. With increased welding time, the fracture mode transitioned from ring-shaped to interfacial, and then to the desired pull-out failure. An increase in welding current also tended to change the fracture mode from interfacial to pull-out failure; however, the relationship was not as strong as with welding time. For all welding conditions where the required nugget diameter was achieved, $100 \%$ pull-out failure was observed.

Analysis of cross-sectioned weld samples gave additional insight into the influence of welding time and current on the nugget growth process. Samples welded with welding system 2 are seen in Fig. 7A-H, where the top row (Fig. $7 \mathrm{~A}-\mathrm{D}$ ) shows the joints at a welding current of $37 \mathrm{kA}$ and a welding time of 20, 30, 50, and $100 \mathrm{~ms}$. The bottom row (Fig. 7E-H) shows the joints at the same welding times but at a 45-kA current level. No significant weld imperfections or irregularities were noted in the welds for any conditions.

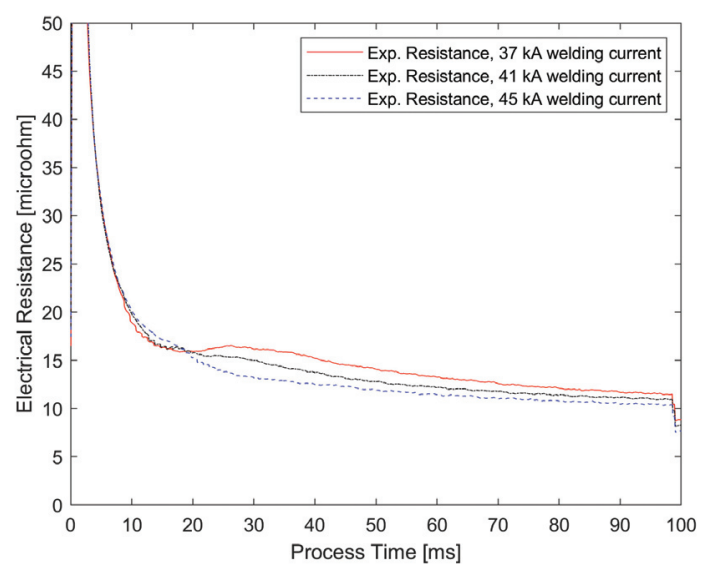

Fig. 13 - Total electrical resistance measured from electrode to electrode for welding system 1 at a 100-ms welding time and with welding currents of 37,41 , and $45 \mathrm{kA}$.

Furthermore, the heat-affected zone revealed by etching of the samples was small, showing efficient heating of the material at the joining interface for the pulse shape used. At both current levels, the fusion zone diameter was similar for welding times of 50 and $100 \mathrm{~ms}$, which was in agreement with pull-out test results. The fusion zone size was a function of welding current; however, the growth rate decreased with welding time independent on current level.

Samples were tested with nondestructive ultrasound testing to observe nugget development at shorter weld times. Ultrasonic testing has an advantage over cross-section imaging because nugget asymmetry is visible and there is no error from failing to section the sample in the middle of the nugget area. The sample results from welding system 2 are seen in Fig. 8. At a welding time of $10 \mathrm{~ms}$, the formation of the weld nugget was incomplete and melting was seen at small, disconnected locations. Beginning at 20-ms weld time, a single nugget had formed, but it was not completely round in shape until $30 \mathrm{~ms}$. Increasing the welding time past $30 \mathrm{~ms}$ resulted in additional nugget growth but at a much lower rate than in the initial stages of nugget nucleation and growth during the first 20 to $30 \mathrm{~ms}$ of welding. The difference in nugget size was not significant between the 50 - and $100-\mathrm{ms}$ welding time samples. Therefore, nugget growth was occurring at a slow rate during this time. Nugget diameter was increased as a function of current level for all welding times; however, the time of nugget nucleation and the overall characteristics of the nugget development process were again shown to be largely independent of the current level.

\section{Weld Nugget Nucleation and Growth}

Simulations were used for further analysis of the weld nugget development processes. While nodal temperature data and final nugget diameter were already available in the simulation software package, a new development was made to the software in cooperation with Swantec for this study to output the dynamic size of the molten zone during the welding process in both the nugget diameter and height di- 


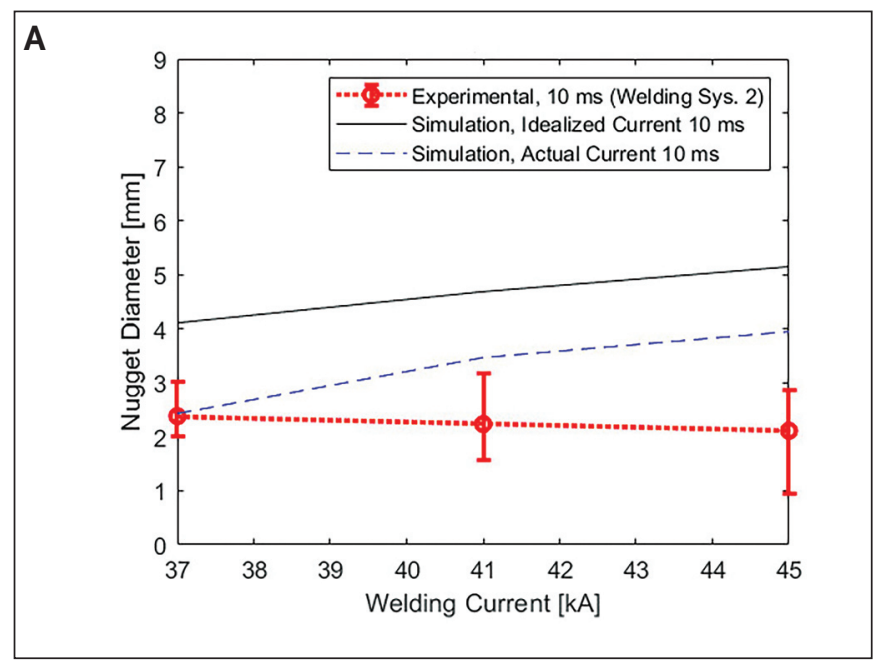

C

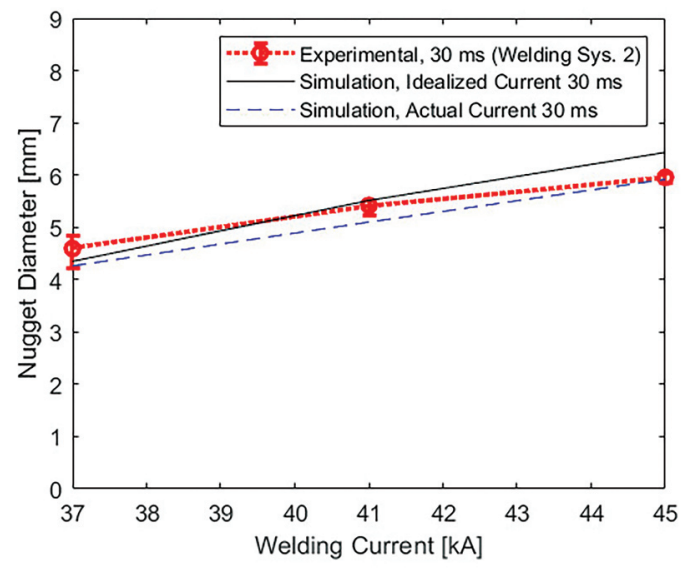

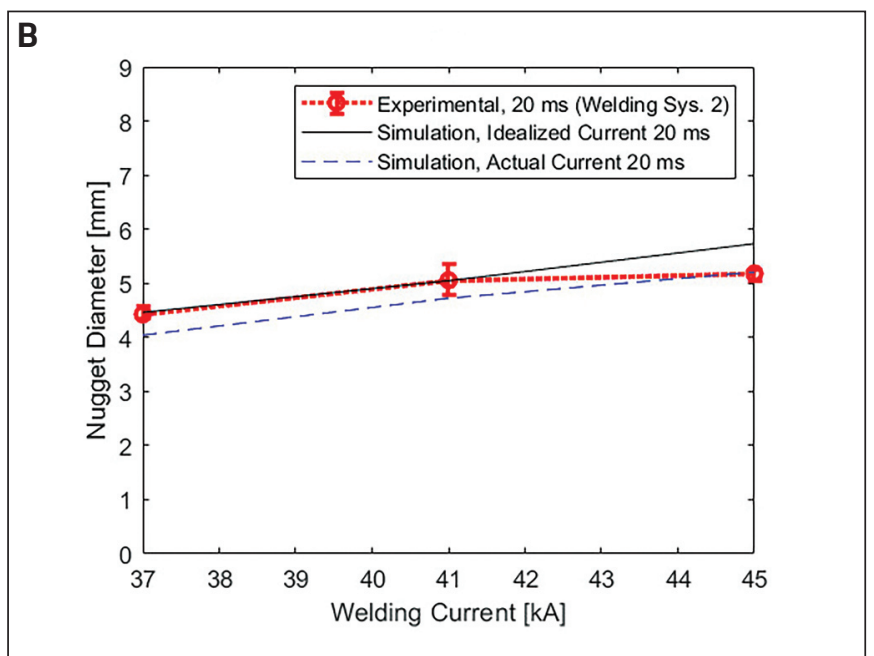

D

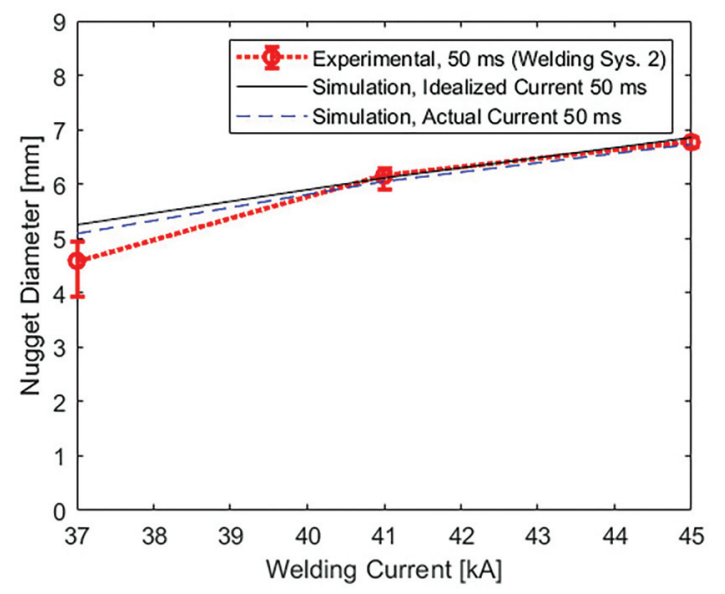

Fig. 14 - Simulations using idealized and actual current profiles: A - 10-ms welding time; B - 20-ms welding time; C - 30-ms welding time; $\mathrm{D}-50$-ms welding time.

rections. With this data, additional information was gained on the nugget development process that was not accessible by experimental testing. The nucleation and growth of the molten zone at different stages in the process are seen for the example of a 100-ms current pulse with $41 \mathrm{kA}$ - Fig. 9.

Analysis of the dynamic nugget diameter data from simulations showed there are two distinct stages in the nugget development process. In the first stage, the weld nugget nucleated and grew rapidly to approximately $60-80 \%$ of its final size. In the simulations, this stage was completed within the first $10 \mathrm{~ms}$ and characterized by the large slope of the nugget diameter vs. time plots - Fig. 10. As compared to experiments, the nugget nucleation stage took place more quickly in the simulations. In evaluation of experimental samples using ultrasound and cross sections, nugget nucleation required 20 to $30 \mathrm{~ms}$ of current application. In this stage, the rapid growth of the nugget likely occurred due to the high contact resistances present. The second stage, called the nugget growth stage, was characterized by a much slower rate of growth of the weld nugget - Fig. 10. While the growth continued until the end of the current application time, the nugget size became almost constant within 70 to $80 \mathrm{~ms}$. In this stage, the slower nugget growth likely took place by heat conduction from the nugget to the surrounding material. Figure 10 contains the dynamic nugget growth curves for the welding time of $100 \mathrm{~ms}$ and three current levels: 37, 41, and $45 \mathrm{kA}$. The presence of the distinct nugget nucleation and growth stages was independent of the current level, and the portion of the process spent in nugget nucleation vs. growth also did not differ greatly by the current level. The simulation data showed some wave-like change in the nugget size during the growth stage, an artifact likely caused by dynamic contact changes during welding.

From the dynamic nugget size data, it was possible to calculate nugget growth rates during the nucleation and growth stages as a function of welding current, the results of which are listed in Table 5. The growth rates in the nucleation stage were significantly greater than in the growth stage, and the time spent in the nucleation stage varied from 6 to $9 \mathrm{~ms}$ depending on current level. The higher heat input rate created by the increased current level led to a higher growth rate during the nucleation and growth stages. The nugget growth was highly linear during the nucleation stage, as evident by the high correlation coefficient between the data and linear approximation line. In the nugget growth stage, the growth rate decreased with time, and linear correlation was weaker than in 

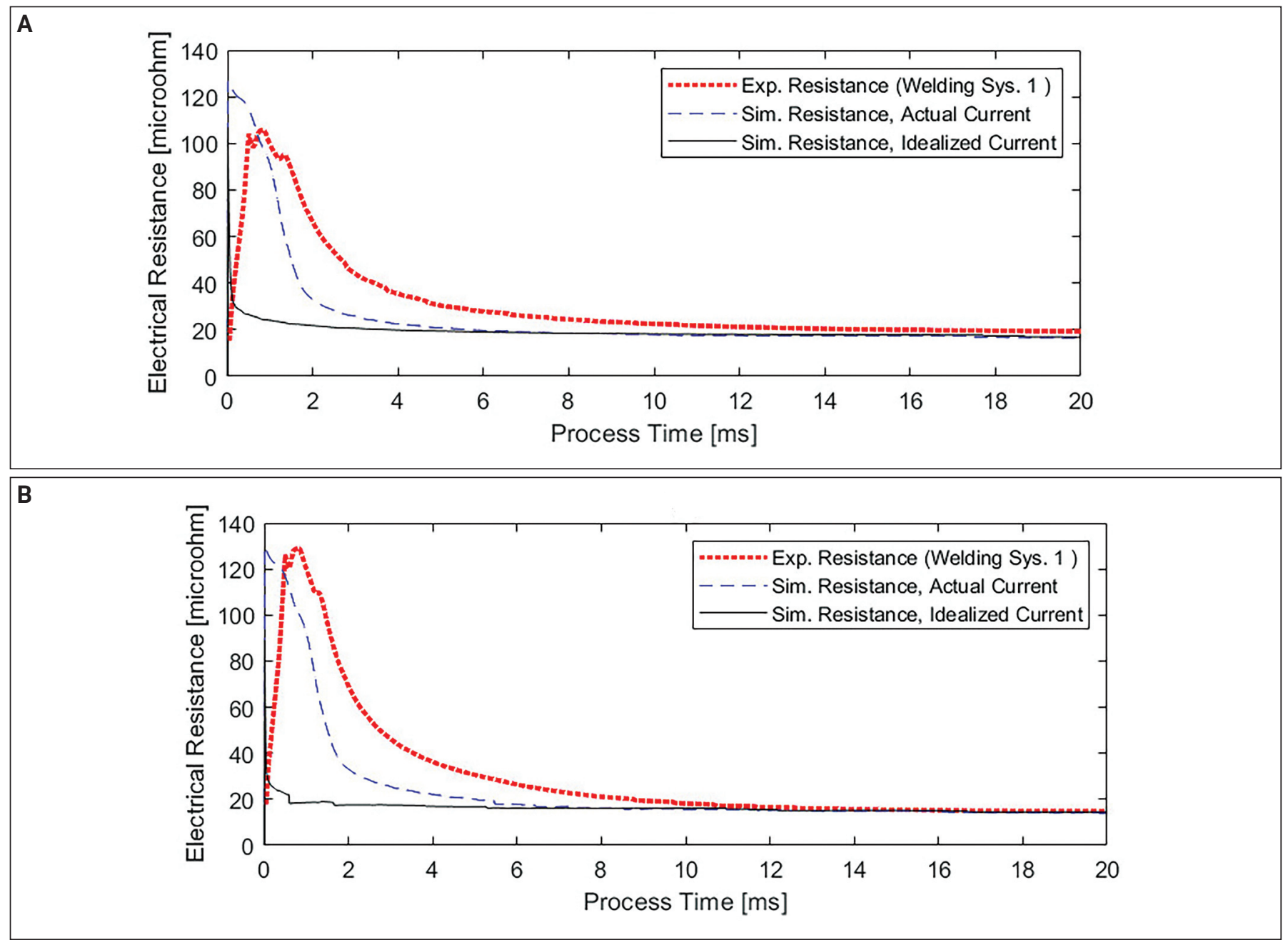

Fig. 15 - Comparison of experimental and simulated resistance profiles with the use of idealized and actual current input profiles. Data shown: $A-27 \mathrm{kA} ; \mathrm{B}-37 \mathrm{kA}$.

the nucleation stage. However, the process became more linear at higher current levels.

\section{Discussion}

The use of short welding pulses reduced the heat input required to generate a weld of a given size. The total heat input to the weld was calculated by measurement of current and voltage signals during welding and an integration of the product of these signals over time. In Fig. 11, the total energy input to the weld is shown for three different welding conditions, all of which produced a weld of a required nugget diameter. For the welding times of 100 and $50 \mathrm{~ms}$, a current level of $43 \mathrm{kA}$ was required. When welding time was further decreased to $30 \mathrm{~ms}, 47 \mathrm{kA}$ was necessary. Although all three conditions produced the same size weld, shorter welding times required far lower heat inputs. The fact that no change in the current level was necessary when the welding time was decreased from 100 to 50 ms suggests that nugget growth is insignificant past $50 \mathrm{~ms}$. This is supported by the experimental data presented in Figs. 6 and 8 as well as the simulation data in Fig. 10.

While the energy requirement can be even further de- creased by a reduction of the welding time to $30 \mathrm{~ms}$, the current level must then be increased by approximately $10 \%$ to partially compensate for the reduction in heat input and to increase the heat input rate. However, the increase in current also creates higher magnetic forces between the gun arms during welding, may cause more rapid electrode wear, and showed inconsistency in results for one of the welding systems tested. Therefore, a reduction of welding time past 50 ms would not be recommended. Nevertheless, reducing the welding time from 100 to $50 \mathrm{~ms}$ generated an energy saving of $48 \%$ per weld spot.

For a fixed pulse shape, the heat input rate was determined by the current level. In Fig. 12, the heat input rate is shown for the same parameter cases presented above. The result showed that the heat input rate to the weld was higher in the case of the 30-ms welding time, where the current level of $47 \mathrm{kA}$ was used. Although the difference in heat input rates did not lead to a difference in weld size, it is evident that it does play a role in the weld nugget formation. For example, the higher heat input rate can compensate for a lower overall heat input to produce an equal weld size, as in the case of the 30-ms weld. Additionally, when materials have high thermal conductivity, such as AA6016-T4 and oth- 
er 6000 series aluminum alloys, the heat input rate must be sufficiently high for a weld nugget to form. Heat produced at the joining interface is quickly conducted away and not utilized for the formation of a weld nugget when the heat input rate is too low. This is evident by the fact that at low current levels and extended welding times, no nugget formation occurred at all. In RSW of steel, long welding times are used for additional nugget growth; however, for highconductivity aluminum materials, this practice would be unsuccessful. Instead, the current level must be sufficiently increased or another parameter solution must be found. This study focused on welding time and current, but the shape of the current pulse also affected the heat input rate. This is another important consideration for short-pulse welding and will be the subject of a follow-up study.

It can be observed that the heat input was not linear and the heat input rate varied with time. Heat input rates were initially very high but then began to decrease at approximately $20 \mathrm{~ms}$. The calculation of heat input for resistance welding is represented by the Joule heating equation in which the heat input for any duration is given by the integral of the product of resistance and the square of the applied current, as seen in Equation 5.

$$
Q=\int_{t_{i}}^{t_{f}} I^{2} R d t
$$

For rectangular-shaped pulses, the applied current is nearly constant. Therefore, the heat input would vary linearly with time were it not for dynamic changes in resistance during welding. The decrease in the heat input rate is a result of the large decrease in resistance that occurs during the breakdown of contact resistances in the first milliseconds of welding. Examples of experimentally measured resistance curves for different current levels are seen in Fig. 13, where the breakdown of contact resistances during the first stages of current application are clearly visible.

The accuracy of welding simulations was influenced by the accuracy of the current profile used and the resulting resistance profiles. The agreement between simulation and experimental results decreased at welding times of less than $20 \mathrm{~ms}$. This disagreement was logical because idealized current profiles were used as inputs to the simulations. While completely rectangular current pulses were programmed as inputs to the welding systems experimentally, they were impossible to achieve due to physical limitations of the current rise speed and control of the current signal during welding. Therefore, a comparison was done where the actual current profiles were recorded during welding and used as the inputs for simulations. The ability to use customized current-profile inputs was an existing capability of the SORPAS software. The result was an improvement in agreement with experimental results at short welding times. In Fig. 14A-D, and especially in Fig. 14A for a welding time of $10 \mathrm{~ms}$, the improvement in agreement with experimental results is evident.

Nevertheless, some disagreement in results still remained for very short welding times (10 ms) and low current levels below $37 \mathrm{kA}$. By observing the difference in the resistance profiles from simulations and measured during experiments, as presented in Fig. 15, one can see that the reason for this was the difference in modeling of the nugget nucleation stage. The breakdown of contact resistances occurred much more quickly in the simulations than in experiments, resulting in a lower amount of heat generated at the start of the welding time. In the nugget growth stage, however, the resistance curves matched between simulations and experiments. Because the nugget nucleation stage represented a much larger fraction of the total process time for short welding times, it played a larger role and the modeling of this stage caused a disagreement in results. At lower welding currents, formation of a weld nugget was highly dependent on the heating occurring at the beginning of the process while contact resistances were high. When the contact resistances were broken down more quickly, as in the simulations, the remaining heat input was not sufficient to form a weld nugget; therefore, the simulation results reported small or zero nugget sizes. The difficulty in modeling the contact resistance breakdown and nugget nucleation helped to explain the discrepancies at short welding times and low welding currents.

The challenge of modeling the breakdown of contact resistances during aluminum RSW and in modeling contact resistance in general is a well-known and universal challenge in finite element analysis (FEA) simulations of the RSW process (Refs. 16, 19). The process is highly complex, especially for aluminum materials due to the presence of oxide layers on the surface of the material, which are broken down in the initial stages of welding. According to Song et al., the contact resistance is highly dynamic during the RSW process and is not only a function of temperature and pressure but also of the condition of the surface (Ref. 20). The surface layers of aluminum alloys are not only complex in their composition and corresponding mechanical and electrical properties but are also highly nonuniform. In the simulations performed, the contact properties were defined uniformly along the contact interfaces. Experience from experiments, as seen in the Fig. 8 ultrasound images at low welding times, shows that nugget nucleation does not always occur uniformly across the contact interface but rather at localized, isolated locations. Therefore, the surface layer and contact properties in reality are not uniform, and heating occurs locally at areas where electrical contact exists prior to the breakdown of the surface layer. The nonuniformity of the surface layer is likely the reason for unsuccessful modeling of the nugget nucleation stage, and this effect is more evident when the nugget nucleation stage plays a larger role in the process, such as at short welding times and at low current levels. This topic remains one of the most significant challenges for FEA modeling of the RSW process for aluminum materials, and future work is necessary to incorporate the nonuniform properties and behavior of the surface layer on a microscale to simulations to further improve numerical results.

Several beneficial impacts are to be gained by the short-pulse MFDC method. Using the short-pulse welding technique, it was possible to reduce the welding time to 50 ms without changing the acceptable current range for welding. The result was a reduction in energy requirement by approximately $48 \%$, in addition to $50 \mathrm{~ms}$ of process time savings per weld. With the increasing importance of carbon emissions reduction and sustainability practices in manufac- 
turing, the decrease in power and energy consumption for welding is an important and promising benefit provided by short-pulse MFDC. Furthermore, the process time savings enable more flexibility in process planning and efficient use of equipment. Additionally, as current levels were not increased by shortening the welding time, issues of gun arm deflections or electrode wear were not evident with the new parameter strategy. In a follow-up study, it will be shown that current levels may even be reduced for thin-sheet combinations of AA6016-T4 compared to standard practices by altering the pulse shape using short-pulse parameterization.

\section{Conclusion}

This paper investigated the use of short-current pulse durations (10-100 ms) as a function of applied current level (27-47 kA) on the RSW of AA6014-T4 using MFDC welding systems. The results have shown that short-pulse welding reduces the heat input necessary for sound welds. The rate of heat input increases with the welding current, thus more efficiently heating and melting the material to be joined. However, a minimum welding time of $50 \mathrm{~ms}$ is necessary for stability in the welding result. Both simulations and experiments suggest the weld nugget formation has distinct nucleation and growth stages in which the fusion zone nucleates on the periphery of the weld nugget and grows inward to the center. The applied current level influences the growth rate and final nugget size but not the nucleation time or shape of the growing weld nugget.

\section{Acknowledgment}

This study was supported by Daimler AG, Sindelfingen, Germany, and is published with their permission.

\section{References}

1. Hirsch, J. 2011. Aluminum in innovative light-weight car design. Materials Transactions 52(5): 818-824. DOI: 10.2320/ matertrans.L-MZ201132

2. Manladan, S. M., Yusof, F., Ramesh, S., Fadzil, M., Luo, Z., and Ao, S. 2017. A review on resistance spot welding of aluminum alloys. International Journal of Advanced Manufacturing Technology 90: 605-634. DOI: 10.1007/s00170-016-9225-9

3. Gould, J. E. 2012. Joining aluminum sheet in the automotive industry - A 30 year history. Welding Journal 91(1): 23-s to 34-s.

4. Zhang, H., and Senkara, J. 2011. Resistance Welding: Fundamentals and Applications. CRC Press: Boca Raton, Fla.

5. Deng, L., Carlson, B. E., and Sigler, D. R. 2018. Effects of electrode surface topography on aluminum resistance spot welding. Welding Journal 97(4): 120-s to 132-s. DOI: 10.29391/2018.97.011

6. Han, L., Thornton, M., Boomer, D., and Shergold, M. 2010. Effect of aluminium sheet surface conditions on feasibility and quality of resistance spot welding. Journal of Materials Processing Technology 210(8): 1076-1082. DOI: 10.1016/j.jmatprotec.2010. 02.019
7. Al Naimi, I. K., Al Saadi, M. H., Daws, K. M., and Bay, N. 2015. Influence of surface pretreatment in resistance spot welding of aluminum AA1050. Production \& Manufacturing Research 3(1): 185-200. DOI: 10.1080/21693277.2015.1030795

8. Li, Z., Hao, C., Zhang, J., and Zhang, H. 2007. Effects of sheet surface conditions on electrode life in resistance welding aluminum. Welding Journal 86(4): 81-s to 89-s.

9. Sigler, D. R., and Karagoulis, M. J. 2011. Weld schedule for resistance spot welding of aluminum alloy workpieces. U.S. Patent Application 2013/0048613.

10. Rusch, H. J., Geßler, R., and Jüttner, S. 2017. Widerstandspunktschweißen von aluminium mit mehrimpulsigem kondensatorentladungsstrom [Resistance spot welding of aluminum with multipulse capacitor discharge current]. Schweißen und Schneiden [Welding and Cutting] 69: 618-619.

11. Rashid, M., Medley, J. B., and Zhou, Y. 2011. Nugget formation and growth during resistance spot welding of aluminium alloy 5182. Canadian Metallurgical Quarterly 50: 61-71. DOI: 10.1179/ $000844311 X 552322$

12. Riedel, F., and Heidrich, J. 2017. Potential of the capacitor discharge welding for difficult-to-weld similar and mixed materials. Joining in Car Body Engineering Conference. Bad Nauheim, Germany.

13. Hwang, I. S., Kang, M. J., and Kim, D. C. 2011. Expulsion reduction in resistance spot welding by controlling of welding current waveform. Procedia Engineering: 2775-2781. DOI: 10.1016/j. proeng.2011.04.461

14. Automobile Industry Association [Verband der Automobilindustrie]. 2013. VDA 239-200: Aluminum Sheet Material. Berlin, Germany.

15. Swantec Software and Engineering ApS. 2018. SORPAS 2D Version 13 User Manual.

16. Zhang, W. 2003. Design and implementation of software for resistance welding process simulations. SAE International Journal of Materials and Manufacturing. DOI: 10.4271/2003-01-0978

17. Crinon, E., and Evans, J. T. 1998. The effect of surface roughness, oxide film thickness and interfacial sliding on the electrical contact resistance of aluminium. Materials Science and Engineering A 242 (1-2): 121-128. DOI: 10.1016/S0921-5093(97)00508-X

18. German Institute for Standardization [Deutsches Institut für Normung]. 2010. DIN EN ISO 5821:2009: Resistance Welding - Spot Welding Electrode Caps.

19. De, A., Thaddeus, M. P., and Dorn, L. 2003. Numerical modelling of resistance spot welding of aluminium alloy. ISIJ International 43(2): 238-244. DOI: 10.2355/isijinternational.43.238

20. Song, Q., Zhang, W., and Bay, N. 2005. An experimental study determines the electrical contact resistance in resistance welding. Welding Journal 84(5): 73-s to 76-s.

ERIC SCHULZ (ewschulz@crimson.ua.edu), MATTHIAS WAGNER, and HOLGER SCHUBERT are with Daimler AG, Sindelfingen, Germany. SCHULZ is also with The University of Alabama, Tuscaloosa, Ala. WENQI ZHANG is with Swantec, Kongens Lyngby, Denmark. BHARAT BALASUBRAMANIAN and LUKE N. BREWER are with the Center for Advanced Vehicle Technologies, The University of Alabama, Tuscaloosa, Ala. 